\title{
A FORMAÇÃO DOCENTE PARA A ABORDAGEM DA EDUCAÇÃO AMBIENTAL NAS ESCOLAS MUNICIPAIS DA SEDE DE ACARAÚ / CEARÁ
}

\author{
Pedro Júlio de Castro Filho iD1 e Eugênio Pacelli Nunes Brasil de Matos iD2
}

\section{Resumo}

O aperfeiçoamento profissional em educação ambiental é um aspecto que permite que o professor desenvolva as condições necessárias para refletir sobre a sua prática e realizar mudanças, na tentativa de oferecer a seus alunos uma abordagem ambiental cada vez mais qualitativa. O objetivo desse estudo foi analisar os aspectos de formação profissional dos docentes do ensino fundamental (60 ao $9^{\circ}$ ano) das escolas municipais da sede de Acaraú-CE para se abordar os conceitos de educação ambiental. Trata-se de um estudo descritivo e foi realizado com 60 docentes de seis escolas municipais de ensino fundamental da sede da cidade de Acaraú-CE, por meio da aplicação de um questionário semiestruturado relacionado aos aspectos de formação e aperfeiçoamento docente na área de educação ambiental e afins. Verificou-se que a maior parte dos docentes não possui formação pedagógica voltada para a educação ambiental, o que reduz as estratégias, os recursos e as metodologias relacionadas com a temática, limitados principalmente pela disponibilidade de tempo, rotina acelerada das escolas e pela baixa oferta de cursos direcionados à formação ambiental.

Palavras-chave: Capacitação; Aperfeiçoamento; Ensino.

\section{TEACHING TRAINING TO APPROACH ENVIRONMENTAL EDUCATION IN MUNICIPAL SCHOOLS IN THE HEADQUARTERS OF ACARAÚ / CEARÁ}

\begin{abstract}
Professional development in environmental education is an aspect that allows teachers to develop the necessary conditions to reflect on their practice and make changes in an attempt to offer their students an increasingly qualitative environmental approach. The aim of this study was to analyze the aspects of vocational training of elementary school teachers (6th to 9th grade) of the municipal schools of Acaraú-CE headquarters to address the concepts of environmental education. This is a descriptive study and was conducted with 60 teachers from six municipal elementary schools of the headquarters of the city of Acaraú-CE, through the application of a semi-structured questionnaire related to aspects of teacher education and improvement in the area of environmental

\footnotetext{
${ }^{1}$ Mestre em Geografia na Universidade Estadual Vale do Acarau (UVA). Especialista em Meio Ambiente e Desenvolvimento Regional pelo Instituto Federal do Ceará (IFCE). Graduado em Ciências Biológicas (IFCE).

${ }^{2}$ Mestre em Ecologia e Recursos Naturais pela Universidade Federal do Ceará. Licenciado em Ciências Biológicas, Especialista em Educação Ambiental. Professor do Instituto Federal do Ceará (IFCE).
}

Perspectivas em Diálogo, Naviraí, v. 09, n. 19, p. 244-261, jan./abr. 2022. 
education and others. It was found that most teachers do not have pedagogical training focused on environmental education, which reduces strategies, resources and methodologies related to the theme, limited mainly by the availability of time, accelerated school routine and low supply of courses aimed at environmental education.

Keywords: Training; Improvement; Teaching.

\section{Introdução}

A relação da educação com o meio ambiente está cada vez mais ampla em diversos sentidos à medida em que se faz necessária a conscientização e integração dos indivíduos para com os desafios do meio ambiente. Sendo assim, a educação ambiental se torna uma temática fundamental na sociedade, uma vez que ela oferece conceitos, métodos e técnicas com o intuito de favorecer a melhor maneira de preservar o meio ambiente (LEFF, 2003).

A Lei Federal no 9.795 de 27 de abril de 1999 determina que a educação ambiental seja trabalhada nas escolas, públicas e privadas, em todos os níveis do ensino (BRASIL, 1999, p. 1), sendo reforçada pelos Parâmetros Curriculares Nacionais para assumir um caráter interdisciplinar (BRASIL, 2002, p. 35). Entretanto, muito do que deve ser trabalhado nas salas de aula em educação ambiental, geralmente recai sobre o professor como uma figura protagonista nesse processo (COIMBRA, 2005).

É direito de cada indivíduo ter uma educação de qualidade que incorpore não somente os valores, as teorias e as práticas em si, mas também os integralize para a prática da cidadania, no que se diz respeito ao meio ambiente. Dessa forma, é indispensável para esse processo que os professores tenham formação adequada para promover aos seus alunos meios para refletirem a respeito de sua importância como cidadãos acerca dos direitos e deveres onde vivem (JACOBI, 2003).

É essencial que logo cedo cada cidadão tenha o conhecimento de como pode atuar e ajudar a cuidar do meio ambiente de forma a conservar os recursos naturais disponíveis e que possa refletir acerca dos problemas ambientais, inserindo essas reflexões na realidade à sua volta (DIAS, 2004).

O presente estudo surgiu a partir da reflexão sobre a existência de uma grande carência no quesito formação profissional para oferecer conhecimentos valiosos acerca da conservação e do cuidado com o meio ambiente aos alunos do ensino fundamental, de maneira a prepará-los para atuarem na realidade em que estão inseridos, sendo indispensável na promoção de um futuro sustentável.

Embora a educação ambiental seja um tema transversal e obrigatória nos currículos escolares, além de um componente importante de caráter transformador para a sociedade, muitas das escolas ainda resistem à essa demanda. Essas escolas são reflexos de um conjunto de fatores que englobam a falta de recursos, a inflexibilidade e organização curriculares, a reflexão dos 
indivíduos como transformantes das causas ambientais, mas principalmente a formação adequada de professores e da gestão escolar (LOUREIRO, 2002).

Esta pesquisa baseia-se na hipótese de que a baixa abordagem da educação ambiental nas escolas é consequência da ausência de formação docente na área.

O objetivo geral deste trabalho foi analisar os aspectos de formação profissional dos docentes do ensino fundamental ( $6^{\circ}$ ao $9^{\circ}$ ano) das escolas municipais da sede de Acaraú-CE para se abordar os conceitos de educação ambiental.

Delinearam-se como objetivos específicos: 1) ressaltar a importância da formação profissional em educação ambiental para a promoção do desenvolvimento sustentável; 2) investigar a formação dos professores para trabalhar com a temática de educação ambiental nas escolas; 3) identificar os principais fatores que interferem na busca do aperfeiçoamento docente em educação ambiental ou áreas afins nas escolas.

A relevância deste estudo reside no fato de que é necessário que a educação ambiental seja trabalhada nas escolas, uma vez que a escola precisa se atentar em promover o desenvolvimento de conhecimentos, habilidades e atitudes necessárias à preservação e à melhoria da qualidade de vida, atentando-se sempre em criar estratégias para minimizar as causas ambientais, contando sempre com profissionais cada vez mais capacitados para oferecer um ensino com mais qualidade.

\section{Breve histórico da implementação da educação ambiental no Brasil}

O estabelecimento da educação ambiental no governo federal do Brasil iniciou-se em 1973 com a criação e implantação do SEMA (Secretaria Especial do Meio Ambiente), mantendo ligação com a Presidência da República. Esta secretaria determinou, como parte de seus encargos, a comunicação e a educação da população brasileira com relação ao uso responsável dos recursos naturais disponíveis, tendo como elemento central a preservação ambiental (MACHADO, 1991).

Anos mais tarde, em 1988, a Constituição Federal, incrementou o inciso VI do artigo 225, a obrigatoriedade da educação ambiental em todos os níveis de ensino e da sensibilização de toda a comunidade para com a conservação do meio ambiente (DIAS, 2004).

Em junho de 1992 ocorreu no Rio de Janeiro a Conferência das Nações Unidas sobre o Meio Ambiente e o Desenvolvimento (Rio-92), a qual teve participação do Ministério da Educação e a produção da Carta Brasileira para Educação Ambiental que foi um dos principais documentos para propiciar a sustentabilidade como plano de sobrevivência global e de melhoria da qualidade de vida (ASSUNÇÃO, 1993).

Durante a Rio-92, a Educação Ambiental passou a ser designada como uma educação crítica da realidade mundial, em que as finalidades apontadas 
para a mesma foram: a consolidação da cidadania para a população mundial (e não a um determinado grupo), efetivando-se pela possibilidade de cada indivíduo possuir direitos e deveres, transformando- se em corresponsável em prol da qualidade de vida; estabelecer uma educação de caráter crítico e inovador, em dois níveis: formal (na escola) e não formal (fora do espaço escolar).

A Agenda 21, documento também concebido e aprovado pelos governos durante a Rio 92, é um plano de ação para ser adotado tanto local quanto globalmente, por organizações do sistema das Nações Unidas, governos e pela sociedade civil, em todas as áreas em que a ação humana impacta o meio ambiente (DIAS, 2004).

No âmbito educacional, o Governo Federal lançou um parecer 226/87 de 11 de março de 1987, apontando que a educação ambiental deveria ser trabalhada de uma maneira interdisciplinar em todos os níveis de ensino (MEC, 1987). O MEC atribui ainda a Portaria 678 de 14 de maio de 1991 que retrata sobre a inserção da educação ambiental nos sistemas de ensino, em todas as modalidades e níveis, sendo considerada e abordada como tema instrucional (MEC, 1991).

Em 1997, em decorrência de muitas discussões acerca da inserção da educação ambiental nos currículos escolares, os Parâmetros Curriculares Nacionais foram autorizados pelo Conselho Nacional de Educação. Esses parâmetros consistem não só de subsídios para as escolas na construção de seu projeto educativo, oferecendo metodologias, valores e ações necessários ao convívio escolar, mas também de apoio no tratamento de temas sociais improrrogáveis e de interesse nacional, conhecido como temas transversais (BRASIL, 2005).

O progresso científico e industrial dos países capitalistas e socialistas implica no impacto em escala global, agredindo e alterando a natureza em prol dos interesses próprios do homem. Nesse sentido, surge a proposta da educação ambiental para a sensibilização dos indivíduos em relação ao ambiente natural do qual fazem parte e como eles podem minimizar as possíveis degradações ambientais (VIOLA, 1987).

A partir desse pressuposto e de outros teoricamente instituídos é que surge a criação da Lei Federal no 9.795 de 27 de abril de 1999 que determina em seu artigo 10 que "a Educação Ambiental será desenvolvida como uma prática educativa integrada, contínua e permanente em todos os níveis e modalidades do ensino formal" (BRASIL, 1999, p. 1).

\subsection{Formação docente em educação ambiental}

A lei 9.795/99 regulamenta que a educação ambiental seja implementada em todos os níveis de ensino e em todas as disciplinas, não sendo inserida como disciplina específica na educação formal, reforçando também a importância da formação profissional dos docentes para abordar a educação ambiental (MEDINA, 2001). 
O professor é o responsável pela execução da temática de educação ambiental nas escolas e isso se deve a partir de seus conhecimentos, representações e intenções no que se refere à educação e à problemática ambiental. Diante do avanço da educação ambiental na educação básica, o professor é colocado diante de exigências às quais ele responde com dificuldade e para as quais os cursos de licenciatura pouco contribuem. Certo distanciamento dos professores da educação ambiental tem como justificativa desde condições de trabalho que dificultam inovações e mais esforços, até a constatação de que não estão preparados para trabalhar com a educação ambiental (CARVALHO, 2008).

A maior parte dos projetos e propostas teóricas que vem sendo produzida no âmbito da pesquisa em educação ambiental está devidamente entrelaçada com ações de intervenção da realidade. Geralmente, a própria oferta de cursos de especialização, projetos de extensão, dentre outros implica na baixa formação profissional em educação ambiental. Assim sendo, a discussão sobre a formação de professores e educação ambiental ainda necessita de maior preocupação por parte dos educadores ambientais e também de um maior aprofundamento sobre o que se tem produzido na área de conhecimento da formação de professores e da definição dos estudos no campo da educação ambiental (GOERGEN, 2010).

A Lei de Diretrizes e Bases da Educação Brasileira, os Parâmetros Nacionais Curriculares e a Política Nacional de Educação Ambiental, assim como as Conferências Internacionais que retratam a temática ambiental, sugerem uma discussão da questão ambiental na formação inicial e continuada dos profissionais da educação. Essas discussões impulsionam a importância do envolvimento da temática ambiental com o ensino, sejam em forma de parâmetros, programas, leis, tratados ou até mesmo estratégias para incluir, em sala de aula, assuntos relacionados a educação ambiental (BRASIL, 2005).

Entretanto, para ensinar sob a concepção da educação ambiental, o professor, não só deve possuir formação pedagógica, como também necessita de uma formação ambiental. Nesse sentido, torna-se indispensável às universidades oferecer aos seus discentes, em sua formação inicial, métodos pedagógicos voltados para a temática ambiental. Isso pode ajudar os futuros professores a estabelecerem e proporem na escola práticas diferenciadas que abranjam a abordagem da educação ambiental, de modo a ajudar o aluno a definir seu papel para com o meio ambiente (ARAÚJO, 2004).

O professor como figura mediadora do conhecimento deve atentar-se sempre em manter os alunos informados acerca das mudanças que ocorrem nos aspectos políticos, socioeconômicos e ambientais. Para tal, é preciso que o profissional esteja cada vez mais engajado em busca de atualizações, seja através de leituras diárias, cursos de aperfeiçoamento, dentre outros que promovam sua procura por informações que possam servir como auxiliadoras em suas práticas pedagógicas (ZAICHNER \& PEREIRA, 2008). 


\section{Metodologia}

Este estudo possui uma abordagem qualitativa, uma vez que permite uma compreensão mais acentuada e integrada acerca do objeto de estudo, dependendo de como o pesquisador concentra sua atuação, ou seja, um estudo que não interfere na dinâmica autêntica pode ser considerado vantajoso e com o potencial para fornecer também informações que vão além de dados numéricos, sendo mais propensos a pesquisas em educação (LÜDKE; ANDRÉ, 1994).

Quanto aos objetivos, o estudo caracteriza-se como uma pesquisa descritiva que, ainda corroborando com Severino (2000), sujeita-se apenas em tratar de registrar e descrever as ocorrências sem interferência nos mesmos, onde é possível observar características e situações. Trata-se também de uma pesquisa de campo, detendo-se à busca de informações acerca de um dado problema e na busca de comprovação de uma hipótese levantada, o que está sujeita à observação dos fatos e na coleta de dados referentes a eles.

\section{1 Área de estudo}

O estudo foi desenvolvido no município de Acaraú que está localizado no litoral oeste do estado do Ceará, sendo delimitado pelos municípios de Cruz, Itarema e Jijoca de Jericoacoara, localizando-se a 232 km da capital Fortaleza.

Segundo a Secretaria Municipal de Educação de Acaraú, a cidade possui seis escolas municipais que se encontram dentro da sede e que abrangem o ensino fundamental do $6^{\circ}$ ao $9^{\circ}$ ano, as quais recebem um maior fluxo de alunos, quando comparadas às demais instituições de outras localidades do próprio município. Nesse sentido, a pesquisa executou-se nessas seis instituições.

O quesito para delimitação da área de estudo deveu-se ao fato de as instituições de ensino encontrarem-se próximas umas das outras, onde foi possível esquematizar a ordem de pesquisa a ser cumprida nas escolas. A relação das escolas em que a pesquisa foi aplicada, bem como a ordem das mesmas está disposta no Quadro 1:

\section{Quadro 1 - Lista das escolas participantes da pesquisa.}

\begin{tabular}{|l|c|}
\hline \multicolumn{1}{|c|}{ Escola } & Localização (bairro) \\
\hline EEIEF Prof. Francisca Silveira Gomes & Pedrinhas \\
\hline EEIEF Teresa de Jesus Silva & Centro \\
\hline EEIEF Deputado José Filomeno & Paulo VI \\
\hline EEIEF Prof. Maria Leonete Brandão & Sítio Buriti \\
\hline EEIEF Dona Eulina Magalhães & Saguim \\
\hline EEIEF Prof. Joelina Ribeiro Ramos Viana & Bailarina \\
\hline
\end{tabular}

Fonte: Do autor, 2020. 


\subsection{Público-alvo}

O critério de inclusão amostral considerou os professores com vínculo de trabalho com a instituição de ensino (efetivos e/ou contratados). Para a participação dos docentes na pesquisa, foi necessário que os responsáveis pelas instituições de ensino estivessem em concordância com o Termo de Autorização deste estudo.

Sendo assim, a pesquisa realizou-se com todos os professores do $6^{\circ}$ ao 90 ano das escolas municipais listadas, dos turnos manhã e tarde, por meio da execução de um questionário semiestruturado. Todos os professores tiveram suas identidades mantidas em sigilo, após preencherem um termo de consentimento para participar da pesquisa.

\subsection{Instrumentos de coleta de dados}

Esta pesquisa realizou-se através de um questionário semiestruturado que consiste na elaboração programada de um roteiro-base, sendo muito importante, pois este método visa a análise de informações que estão à parte do roteiro, podendo ser incorporadas à pesquisa, valendo-se de vivências, histórias e ocorrências que muitas das vezes estão ocultas em muitas técnicas de pesquisa, ou seja, o pesquisador consegue absorver informações para além das pré-estabelecidas em seu roteiro (REA; PARKER, 2000).

$\mathrm{O}$ questionário semiestruturado foi composto por perguntas abertas e fechadas, em que nelas se abordaram os aspectos de formação profissional dos envolvidos. O questionário dividiu-se em duas seções: a primeira seção correspondeu ao perfil dos professores e suas formações, e a segunda parte envolveu os aspectos de aperfeiçoamento docente em educação ambiental e as dificuldades associadas.

\subsection{Análise e interpretação dos dados}

A etapa do questionário semiestruturado passou por uma análise crítica e minuciosa, em que foram observadas as respostas e informações complementares referentes a cada item. Em perguntas abertas, os dados foram interpretados através da técnica de análise de conteúdo que, de acordo com Bardin (2011, p. 47) caracteriza-se como:

[...] um conjunto de técnicas de análise das comunicações visando a obter, por procedimentos sistemáticos e objetivos de descrição do conteúdo das mensagens, indicadores (quantitativos ou não) que permitam a inferência de conhecimentos relativos às condições de produção/recepção (variáveis inferidas) destas mensagens.

A técnica de análise que foi utilizada nas perguntas fechadas consiste na utilização da escala de Likert, sendo descritos por meio de ilustrações e tabelas. De acordo com Appolinário (2011, p. 81), este método consiste em um "tipo de 
escala de atitude na qual o respondente indica seu grau de concordância ou discordância em relação a determinado objeto". Em outras palavras, esta escala utiliza diversas formas de gradação (Ex.: Nunca, Raramente, Ocasionalmente, Frequentemente, Sempre), o que está relacionada com a intensidade das respostas dos participantes.

Além disso, Gil (2008) destaca a importância de uma eficiente elaboração de um questionário, o que contribui para a facilidade na operacionalização dos resultados. Os itens contidos no questionário obedeceram a uma sequência lógica, a qual favoreceu o processamento das informações e ao longo da análise dos dados foram criadas categorias de análise para facilitar a compreensão e os resultados que se obteve.

\section{Aspectos da formação docente no Ensino Fundamental para a abordagem da Educação Ambiental}

\subsection{Análise do perfil profissional}

Decorrente da análise dos dados obtidos, foi possível verificar que a quantidade de profissionais que participaram da pesquisa superou mais de $90 \%$ do total de professores atuantes no ensino fundamental ( $6^{\circ}$ ao $9^{\circ}$ ano) da sede do município de Acaraú-CE, estando representado na Tabela 1:

Tabela 1 - Relação de participantes da pesquisa por unidade escolar

\begin{tabular}{cccc} 
Escola & Participantes & \multicolumn{2}{c}{ Situação profissional } \\
Efetivo & Temporário \\
\hline $\begin{array}{c}\text { Prof. Francisca Silveira } \\
\text { Gomes }\end{array}$ & 12 & 04 & 08 \\
\hline Teresa de Jesus Silva & 15 & 04 & 11 \\
\hline Prof. Joelina Ribeiro Viana & 15 & 05 & 10 \\
\hline Deputado José Filomeno & 06 & 03 & 03 \\
\hline Prof. Maria Leonete Brandão & 06 & 03 & 03 \\
\hline Dona Eulina Magalhães & 06 & 02 & 04 \\
\hline TOTAL & $\mathbf{6 0}$ & $\mathbf{2 1}$ & $\mathbf{3 9}$ \\
\hline
\end{tabular}

Fonte: Do autor, 2020.

Vale mencionar que 06 docentes optaram por não participar do estudo e os fatores que influenciaram nessa decisão estavam relacionados com a disponibilidade de tempo, múltiplas tarefas, resolução de problemas, preparação de aula, horários corridos, dentre outros.

De acordo com as informações prestadas nos questionários, evidenciouse que a maior parte dos professores é do sexo feminino (65\%) e que a faixa etária em que se concentra aproximadamente 64\% dos docentes está entre 31 e 40 anos. Além disso, a maioria dos professores possui, em média, um tempo 
de atuação no ensino fundamental superior a 05 anos e no que se refere à situação profissional, $65 \%$ dos docentes são temporários nas escolas.

A partir da análise sobre a formação acadêmica dos docentes das escolas pesquisadas, verificou-se que a quantidade representativa de profissionais que possuem licenciatura em matemática nas referidas instituições de ensino chegou a $33 \%$ do total de participantes, seguidos de cerca de $17 \%$ licenciados em pedagogia e $15 \%$ em biologia. Já as demais licenciaturas tiveram um percentual igual ou menor que $10 \%$ (Gráfico 1).

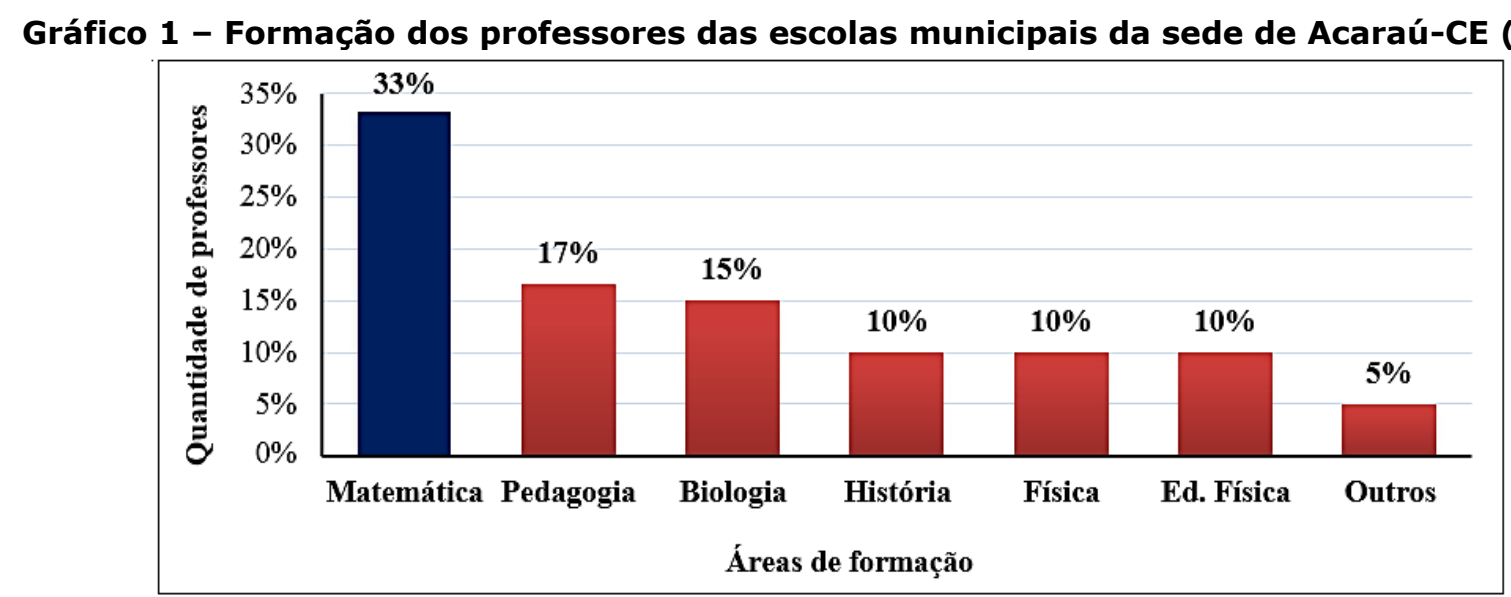

Fonte: Do autor, 2020.

É fundamental frisar sobre a importância do vínculo de trabalho em caráter efetivo dos docentes na escola, pois permite e propicia a criação, o desenvolvimento e o acompanhamento de projetos que possam surgir nas instituições a longo prazo, principalmente os que se referem à temática de Educação Ambiental, já que se constitui de um processo lento, contínuo e gradual (SORRENTINO, 2001).

Nesse sentido, vale destacar que todos devem estar envolvidos com as problemáticas ambientais como um processo integrado e indissociável à formação cidadã. Desta forma, nas escolas, os professores precisam abordar a educação ambiental em suas práticas pedagógicas como rege os documentos oficiais de maneira integrada e contextualizada, uma vez que esta possui um caráter transdisciplinar (CARNEIRO, 2011).

\subsection{Análise dos aspectos de aperfeiçoamento docente}

Esta etapa do estudo se comprometeu em verificar como os professores lidam com o processo de aperfeiçoamento na área ambiental para proporcionar a seus alunos os conceitos voltados para o meio ambiente. Vale ressaltar que as narrativas dos docentes foram mantidas em sigilo durante às análises e preferiuse identificá-los como P1, P2, P3 e assim por diante em alguns momentos. 
A partir da análise da segunda parte do questionário destinada aos aspectos de aperfeiçoamento pedagógico, ou seja, as atividades realizadas, a preparação profissional e as dificuldades que os professores têm para se aprimorarem com a temática ambiental, evidenciou-se que quando se trata do conhecimento da legislação em vigor no sistema de ensino brasileiro, no que se refere à EA, a maior parte dos professores não possuem conhecimento acerca da mesma (Gráfico 2).

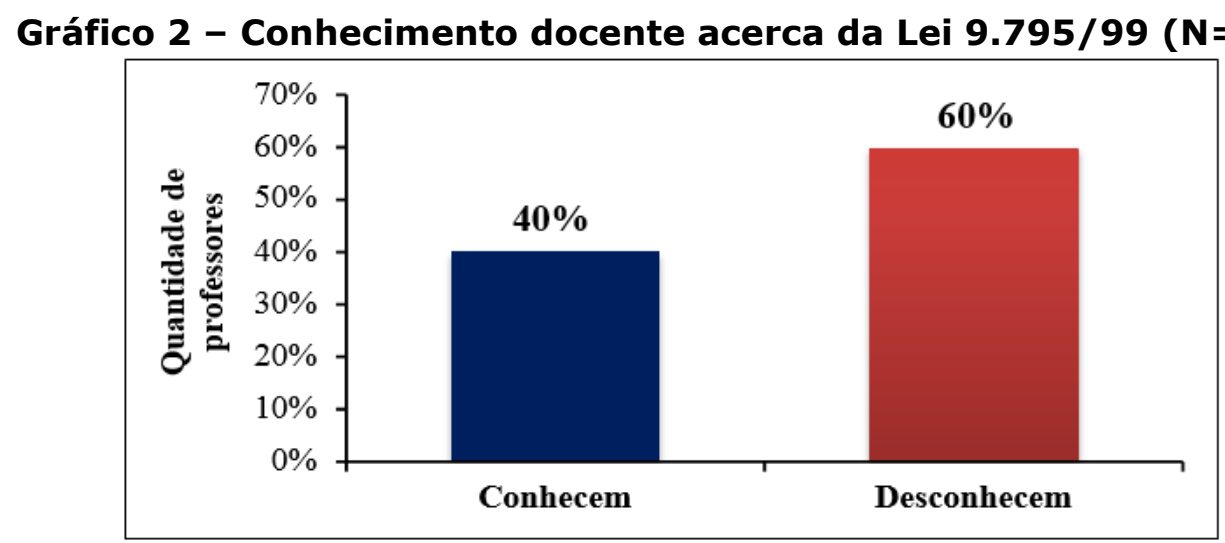

Fonte: Do autor, 2020.

No que se refere à frequência com que os professores abordam os conteúdos de educação ambiental em suas aulas, foi possível verificar que $70 \%$ dos participantes trabalham com a educação ambiental de maneira ocasional em suas práticas pedagógicas, enquanto que $5 \%$ nunca trabalhou com a educação ambiental, como demonstrado no Gráfico 3:

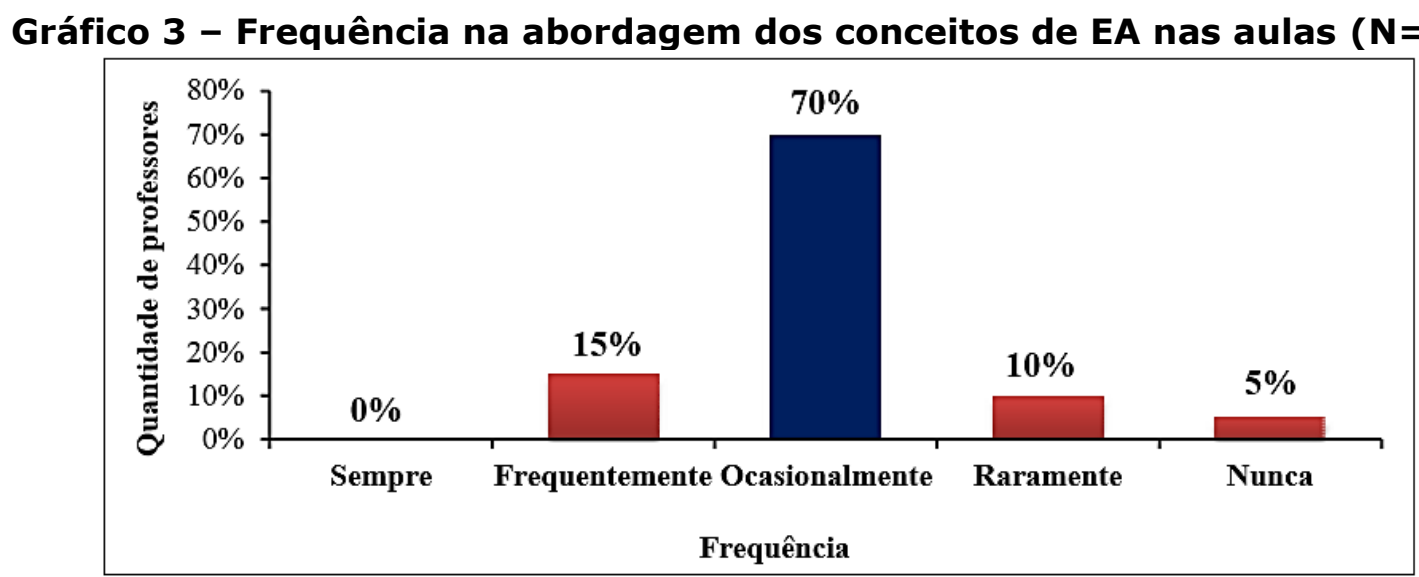

Fonte: Do autor, 2020.

Além disso, vale destacar que apenas $1 / 3$ dos docentes que conhecem a lei, já a leram na íntegra. Desta forma, é correto afirmar que a educação ambiental é tida ainda como uma área de conhecimento em fase de desenvolvimento, cercada por contradições e com um contexto histórico que dificulta o seu processo de assimilação (MEDINA, 2001). 
É possível destacar que a abordagem da EA nas práticas pedagógicas dos docentes nem é tão comumente exercida como também não deixa de ser presente em momentos específicos do trabalho docente. Torna-se essencial destacar que a abordagem da EA nas salas de aula perpassa inicialmente pela preparação do professor para trabalhar com tal temática. Esse fator relacionase diretamente com a formação de professores, sendo que esta é responsável por subsidiar os docentes em suas práticas pedagógicas (GUIMARÃES, 2007).

Ressalta-se que os aspectos de formação inicial dos professores é um quesito fundamental na aquisição de estratégias metodológicas de ensino e quando a formação ambiental não é inserida na trajetória acadêmica dos professores, é muito provável que estes venham a não saber como trabalhar ou a melhor maneira de abordar a EA na escola (TOZONI-REIS \& CAMPOS, 2014).

É deste modo que as universidades têm um desafio grandioso na promoção de conceitos relacionados com o meio ambiente, visando a construção de atitudes e formação de profissionais cada vez mais responsabilizados com as causas ambientais (SORRENTINO \& NASCIMENTO, 2010).

No que tange sobre a relevância da temática ambiental para as aulas dos docentes, verificou-se que mais da metade (65\%) não consideram que a educação ambiental deva ser abordada em suas aulas, seja porque estas deviam ser mais trabalhadas sob o domínio das áreas das ciências naturais ou pela disponibilidade de tempo, como mencionado nas passagens, a seguir:

A educação ambiental é importante para a formação do aluno, mas cabe mais aos professores de ciências abordar com ênfase essa temática (P1).

Existem muitas tarefas para o professor realizar mediante o que é proposto pela escola que muitas das vezes não conseguimos abordar todas os temas que são indicados, devido ao tempo (P2).

Geralmente, a tarefa de abordar assuntos relacionados com o meio ambiente recai somente sobre os professores das áreas de Ciências Naturais, sendo deixada de lado pelos docentes responsáveis por outras áreas do conhecimento. Esse distanciamento dos professores da responsabilidade social com o meio ambiente contribui para que cada vez mais os alunos saiam da escola sem uma bagagem de experiências e atitudes voltadas para a conservação do meio ambiente (RODRIGUES, 2009). Além disso, destaca-se que:

A EA é tida como uma prática transdisciplinar e possui como objetivos a construção de valores e práticas que não apenas almejam a conscientização ambiental, mas também a sua sensibilização, sendo desenvolvidos pensamentos de enternecimento no ambiente em que se vive (REIGOTA, 2011, p. 35).

Os docentes quando perguntados sobre os atributos alcançados durante a formação inicial para o aperfeiçoamento em educação ambiental, mais da metade dos relatos dos professores destacaram que quase não tiveram uma formação ambiental em sua trajetória acadêmica. 
Quase nunca eram abordados conceitos de educação ambiental e meio ambiente durante o curso. As atividades eram muito rápidas e geralmente eram palestras e poucas oficinas (P3).

Entretanto, vale ressaltar que referente aos professores que tiveram a temática ambiental envolvida durante sua formação inicial, estas contribuíram para o alcance de metodologias diversificadas e recursos metodológicos diferenciados para abordar a educação ambiental na sala de aula.

Durante a universidade tivemos um contato com o meio ambiente de uma forma mais direta e muitas técnicas e métodos repassados, utilizo durante as minhas aulas (P4).

Essas informações quando unidas aos dados verificados no Gráfico 2, faz com que seja possível também relacionar o baixo acesso à demanda legal aos aspectos de formações desses profissionais, ou seja, muitos dos profissionais pesquisados alegaram não obter a educação ambiental em suas graduações, o que já contribui para a baixa acessibilidade aos conceitos, às técnicas, às estratégias e às legislações que permeiam a mesma.

Ademais, evidenciou-se também que a educação ambiental é tida nos currículos escolares nos âmbitos das universidades apenas no que se refere às áreas da natureza ou afins, o que contribui para uma formação deficiente no quesito ambiental dos profissionais de outras graduações.

Os docentes quando indagados sobre a oferta de cursos e atividades de aperfeiçoamento docente relacionadas com o meio ambiente promovidas pela Secretaria de Educação Municipal e pelas instituições de ensino em que exercem, a maior parte deles $(60 \%)$ destacaram que raramente são proporcionadas atividades de capacitação docente em EA. Basicamente essas atividades são refletidas em encontros eventuais para discutir a temática ambiental nas próprias escolas.

Além disso, no que se refere à frequência que os professores buscam aperfeiçoamento na área ambiental, foi evidenciado que $40 \%$ alegaram que realizam de maneira rara, enquanto que $20 \%$ realizam frequentemente como forma de manterem-se atualizados sobre a temática ambiental (Gráfico 4):

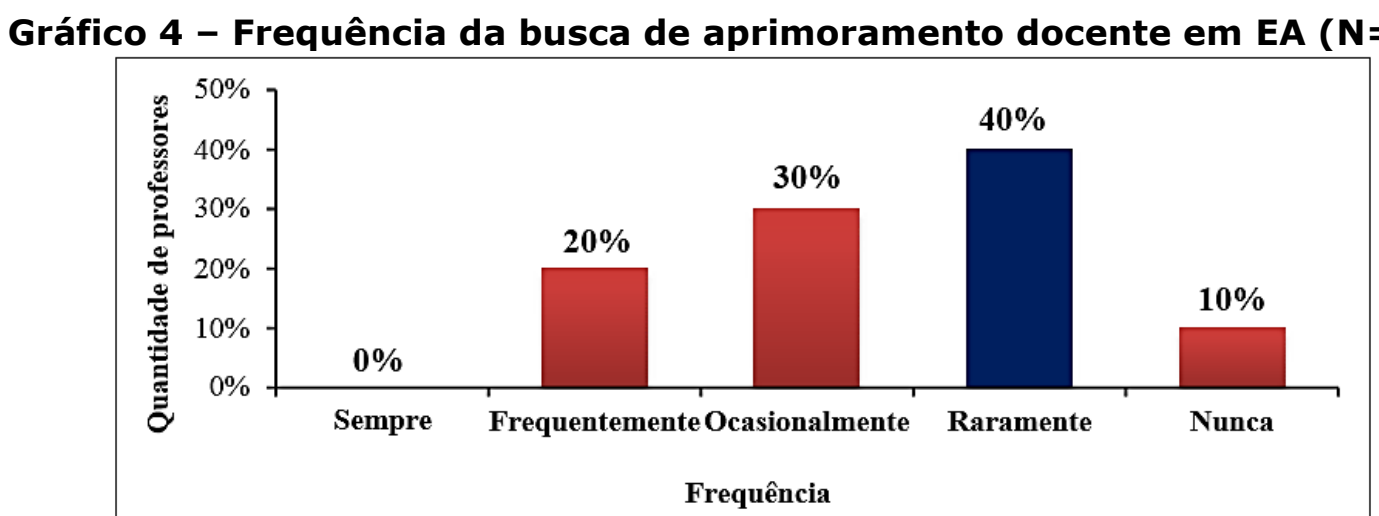

Fonte: Do autor, 2020. 
As atividades de aperfeiçoamento que os docentes realizam como método de alcançar uma formação ambiental para exercer nas salas de aula são refletidas em cursos EaD em EA ou áreas afins (35\%), projetos de EA na escola $(25 \%)$, pós-graduação (15\%) e outros (15\%), conforme o Gráfico 5:

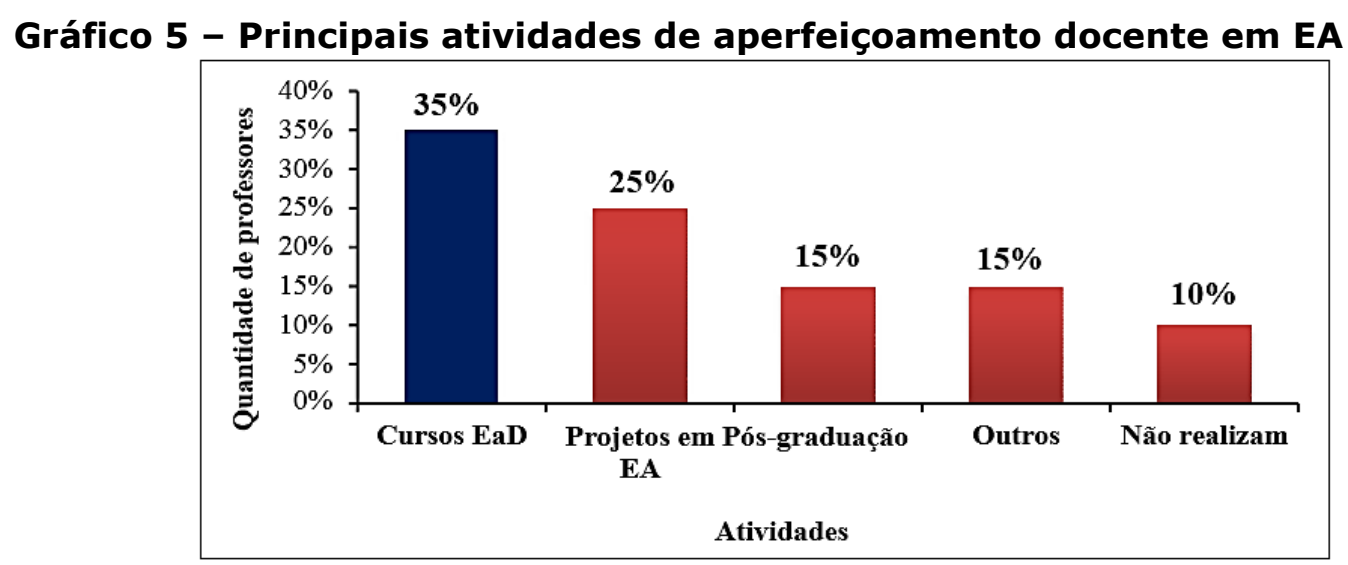

Fonte: Do autor, 2020.

A partir dos dados apontados no Gráfico 4, evidenciou-se uma relação entre os dados apresentados juntamente com Gráfico 5, dos quais as atividades de aperfeiçoamento estão diretamente relacionadas com a implementação da educação ambiental nos currículos acadêmicos nas formações docentes.

Como principal atividade de aprimoramento, destacam-se os cursos à distância que, de acordo com Anohina (2005), caracteriza-se como uma modalidade de ensino que permite com que os alunos utilizem materiais de aprendizagem por conta própria, embora haja a presença de um professor, cuja função é dar suporte e tutorias.

Muitos dos profissionais de ensino aderem a esta forma de aperfeiçoamento em detrimento da concentração de atividades rotineiras e da disponibilidade de tempo, que muitas das vezes tendem a distanciar o professor da capacitação profissional para o exercício do magistério (OLIVEIRA, 2006). Entretanto, alguns docentes participam de projetos de EA (desenvolvidos pela escola ou de cunho particular) e pós-graduação na área de EA ou afins, os quais conseguem desenvolver atividades de EA.

Com relação às dificuldades encontradas pelos professores acerca da busca pelo aperfeiçoamento profissional em EA, encontram-se o tempo (aproximadamente $65 \%$ ) e a rotina escolar (50\%) como os principais fatores que acometem esse quadro (Gráfico 6). 


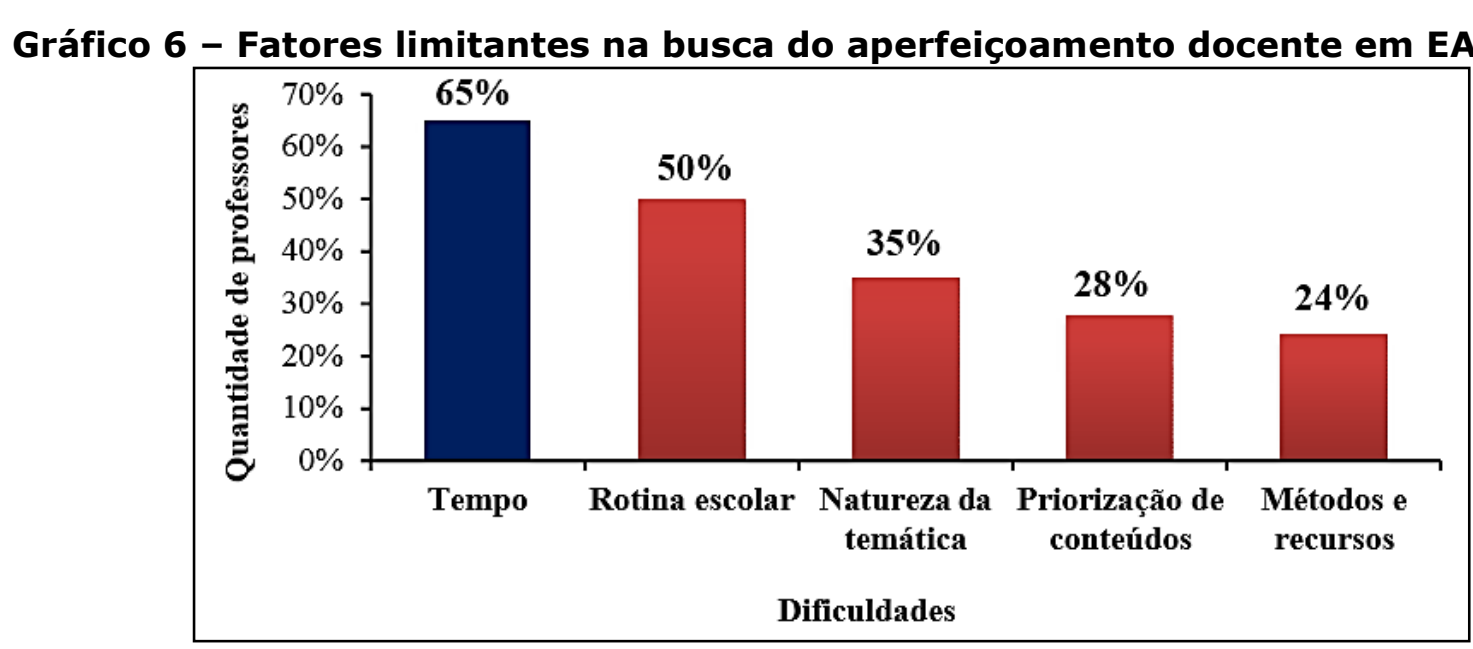

Fonte: Do autor, 2020.

Percebe-se, a partir do reflexo dos dados apresentados, que a principal dificuldade dos professores para realizar atividades de aprimoramento profissional em EA gira em torno da disponibilidade de tempo e da rotina escolar.

É comum observar que os professores enfrentam muitos desafios em suas práticas pedagógicas como a superlotação das salas de aula, entrega de diários escolares, correção de provas e atividades, tornando mais difícil conseguir um momento para desenvolver a EA em sua prática, assim como para se aperfeiçoar (SACRISTAN, 2000).

Entretanto, vale ressaltar a necessidade e o papel do planejamento na organização, flexibilização e domínio do trabalho docente, pois permite que o professor consiga administrar melhor suas práticas pedagógicas, busque aperfeiçoamento profissional e consiga trabalhar a EA de forma mais fluida e diversificada com os alunos, atentando-se às regulamentações e metas estabelecidas pela escola (CARVALHO, 2008).

Outras dificuldades associadas constituem-se pelo distanciamento da temática ambiental com a disciplina exercida pelos professores e da priorização de outros conteúdos como mais "importantes" para a formação do aluno, ou seja, os docentes possuem dificuldade de incrementar a EA em suas aulas pela ausência ou baixa formação na temática referida, o que impacta também na seleção dos métodos e recursos mais adequados.

É preciso que a EA seja encarada como uma aliada essencial no combate à degradação ambiental, sob uma perspectiva de transformação de atitudes e valores voltados para o meio ambiente, onde a escola deve possuir como uma de suas atribuições a de formar o sujeito para o exercício da cidadania, o que inclui respeitar, cuidar e disseminar sobre o meio ambiente (BERNA, 2001).

Com relação ao último item do questionário referente ao que poderia ser feito para diminuir essas dificuldades em EA, os professores em sua maioria indicaram a oferta de cursos por parte dos órgãos responsáveis e pelas instituições escolares, voltados para o aperfeiçoamento pedagógico relacionado com a temática ambiental. 
Outra possível alterativa presente nas narrativas docentes, abrange a existência de um tempo disponibilizado pela escola para que os professores possam desenvolver atividades de EA e para se aperfeiçoar, uma vez que o tempo é um forte fator (como mencionado no Gráfico 6) que limita a busca de aprimoramento.

Com tantas ocupações para fazer e conteúdos importantes para executar, é difícil focar sobre o meio ambiente com tanta frequência durante as aulas, mas que seria o contrário, caso houvesse um tempo dedicado para isso (P5).

Nesse sentido, a realidade dos dados apresentados contribui para uma compreensão mais acentuada sobre o quadro atual de formação profissional o qual a educação ambiental está inserida nas escolas municipais da sede de Acaraú-CE.

É importante destacar que a formação profissional é um quesito que garante ao docente as múltiplas estratégias de ensino, munindo-os de técnicas, procedimentos e reflexões que são indissociáveis da prática docente, sendo que na educação ambiental também não é diferente, pois é preciso que os docentes estejam engajados sobre as mudanças que ocorrem entre as relações homemnatureza para que se possa desenvolver juntamente com seus alunos esses conceitos, proporcionando, na medida do possível, um ensino com mais qualidade (DIAS, 2004).

\section{Considerações finais}

Abordar a temática ambiental sempre foi um grande desafio para o professor e se torna cada vez mais complexo, uma vez que a sociedade está cada vez mais distanciada do meio ambiente. É reconhecível a importância da prática da educação ambiental em todos os segmentos do ensino e percebe-se que não há um interesse por parte dos docentes em fazer desta uma temática comum nas aulas.

A partir das informações refletidas neste estudo, foi possível verificar que os aspectos de formação profissional em EA dos professores encarregados pelo ensino fundamental ( $6^{\circ}$ ao $9^{\circ}$ ano) das escolas municipais da sede de AcaraúCE ainda são escassos, necessitando de uma atualização nesse quesito, o que impacta diretamente nas práticas pedagógicas como um todo.

Torna-se fundamental que as universidades se posicionem a respeito de sua responsabilidade para com as preocupações ambientais, inserindo a dimensão da Educação Ambiental nos seus sistemas de gestão, sendo possível promover o envolvimento e a integração de pessoas e grupos que atuam nessa área e o aperfeiçoamento do sistema de comunicação entre os membros da comunidade acadêmica.

Destaca-se também a ausência de cursos de formação continuada em EA por parte dos órgãos competentes e o descompromisso de alguns profissionais, dentre eles, direção, coordenação pedagógica e os próprios docentes para o 
desenvolvimento dessa prática pedagógica. É a partir desse quadro que se pode afirmar que o exercício do aperfeiçoamento em EA precisa ser melhor e mais enfatizado pelos professores, não porque seja uma exigência do Ministério da Educação, mas porque acredita-se ser a maneira mais cabível para proporcionar atitudes e mudanças necessárias à formação cidadã para atuar na sociedade.

$\mathrm{Na}$ finalização deste estudo, espera-se contribuir com futuras pesquisas e trabalhos realizados na área, quer seja para estudantes da comunidade local e externa, quer seja para professores e demais profissionais com objetivo de melhoria da educação como um todo.

\section{REFERÊNCIAS}

ALVES, José Augusto Lindgren. Relações Internacionais e Temas Sociais, a década das Conferências. Brasília, IBRI, 2001.

ANOHINA, Alla. Analysis of the terminology used in the field of virtual learning. Educational Technology \& Society, v. 8, p. 91-102, 2005.

APPOLINÁRIO, Flávio. Dicionário de metodologia científica: um guia para a produção do conhecimento científico. Ed. Atlas. São Paulo, 2011.

ARAÚJO, Maria Inêz de Oliveira. A Universidade e a Formação de Professores para a Educação Ambiental. Revista Brasileira de Educação Ambiental - REVBEA, No . 0, p.70 - 78, novembro2004. Disponível em: https://d3nehc6yl9qzo4.cloudfront.net/downloads/revbea_n_zero.pdf. Acesso em: 27 abr. 2020.

ASSUNÇÃO, Lucas. "Rio-92: perdemos nossa última chance?". Revista de Administração, vol. 28, n.3. São Paulo, p. 93-97, 1993.

BARDIN, Laurence. Análise de conteúdo. São Paulo: Edições 70, 2011.

BERNA, Vilmar. Como fazer educação ambiental. São Paulo: Paulus, 2001.

BRASIL. Política Nacional de Educação Ambiental. Lei no 9.795 de 27 de abril de 1999. Dispõe sobre a educação ambiental, institui a Política Nacional de Educação Ambiental e dá outras providências. Diário Oficial da União, Brasília, DF, 28 de abril de 1999. Seção 1, p. 41. Disponível em: http://www.planalto.gov.br/ccivil_03/leis/19795.htm. Acesso em 07 Abr. 2020.

BRASIL. Ministério da Educação. Secretaria da Educação Fundamental. Média e Tecnológica. Parâmetros Curriculares Nacionais + $(\mathbf{P C N}+)$. Meio ambiente, saúde. Vol.9. Brasília: MEC, 2002, 128p.

BRASIL. Ministério da Educação e Ministério do Meio Ambiente. Programa Nacional de Educação Ambiental - ProNEA. $3^{a}$ ed. Brasília: MMA, 2005. Disponível em: http://portal.mec.gov.br/secad/arquivos/pdf/educacaoambiental/pronea3.pdf. Acesso em: 30 maio 2020. 
CARNEIRO, Silvia Lignon. Escola Amigos do Verde: resiliência, amorosidade e ciência para a sustentabilidade. 1 ed. Porto Alegre: Armazém Digital. 2011.

CARVALHO, Isabel Cristina de Moura. Educação Ambiental: a formação do Sujeito Ecológico. $4^{\mathrm{a}}$ ed. São Paulo: Cortez, 2008.

COIMBRA, Audrey de Souza. Interdisciplinaridade e Educação Ambiental: integrando seus princípios necessários. Revista Eletrônica do Mestrado. Educação Ambiental. ISSN 1517-1256, Volume 14, janeiro a junho de 2005.

DIAS, Genebaldo Freire. Educação ambiental: princípios e práticas. 9.ed. São Paulo: Gaia, 2004.

GIL, Antonio Carlos. Métodos e técnicas de pesquisa social. 4 ed. São Paulo: Atlas, 207p. 2008.

GOERGEN, Pedro. Teoria e ação no GT educação ambiental da ANPEd: partilhando algumas suspeitas epistemológicas. Pesquisa em educação ambiental, vol. 5, n. 2. P. 9-30, 2010.

GOOGLE EARTH-MAPAS. Disponível em: http://mapas.google.com. Acesso em: 29 maio 2020.

GOMES, Romeu. A análise de dados em pesquisa qualitativa. In: MINAYO, Maria Cecília de Souza (Org). Pesquisa Social. 23.ed. Rio de Janeiro: Vozes, 2004.

GUALDA, Regina Elena Crespo. Política nacional do meio ambiente: formação de recursos humanos e universidade. In: IBAMA. Seminários: Universidade e meio ambiente. Documentos básicos. Brasília: [s.d.], p. 19-21, 1990.

GUIMARÃES, Mauro. A dimensão ambiental na educação. ed. $8^{\text {a }}$. Papirus. São Paulo, 2007.

JACOBI, Pedro Roberto. Educação ambiental, cidadania e sustentabilidade. Cadernos de Pesquisa, n. 118, p. 189-205, 2003.

LEFF, Enrique. A complexidade ambiental. São Paulo: Cortez, 2003.

LOUREIRO, Carlos Frederico Bernardo. (orgs.). Educação ambiental: repensando o espaço da cidadania. São Paulo: Cortez, 2002.

LÜDKE, Menga; ANDRÉ, Marli. Pesquisa em educação: abordagens qualitativas. São Paulo: EPU, 1994.

MACHADO, Paulo Affonso Leme. Direito Ambiental brasileiro. 3. ed. São Paulo: Revista dos Tribunais, 595 p. 1991.

MEDINA, Naná Mininni. A formação dos professores em Educação Ambiental. In: Panorama da educação ambiental no ensino fundamental / Secretaria de Educação Fundamental - Brasília: MEC; SEF, 2001.

MINISTÉRIO DA EDUCAÇÃO E DESPORTO/Conselho Federal de Educação. Parecer 226/87. Documenta. Brasília: [s.d.], 1987. 
MINISTÉRIO DA EDUCAÇÃO E DESPORTO. Política de Educação Ambiental: linhas de ação. Brasília: Assessoria de Educação Ambiental da Secretaria Executiva do MEC, 12 p. 1991.

OLIVEIRA, Elsa Guimarães. A EaD na Transição Paradigmática. SP: Papirus, 2006.

REA, Louis M.; PARKER, Richard. A. Metodologia de pesquisa: do planejamento à execução. Trad. Nivaldo Montingelli Jr. São Paulo: Pioneira, 2000.

RODRIGUES, Denise Celeste Godoy de Andrade. Ensino de Ciências e a Educação Ambiental. Revista Práxis, ano I, n. 1, jan. 2009.

SACRISTAN, José Gimeno. O currículo - Uma reflexão sobre a prática. Porto Alegre: Artmed, 2000.

SEVERINO, Antônio Joaquim. Metodologia do trabalho científico. São Paulo: Cortez, 2000.

SORRENTINO, Marcos. Reflexões sobre o panorama da educação ambiental no ensino formal. Panorama da educação ambiental no ensino fundamental. Brasília: MEC; SEF, 2001.

SORRETINO, Marcos. NASCIMENTO, Elimar Pinheiro do. Universidade e políticas públicas de educação ambiental. Educ. Foco. Juiz de Fora. p. 15-38, 2010.

TOZONI-REIS, Marília Freitas de Campos; CAMPOS, Luciana Maria Lunardi. Educação ambiental escolar, formação humana e formação de professores: articulações necessárias. Educ. rev., Curitiba, n. 3, p. 145-162, 2014.

VIOLA, Eduardo José. O movimento ecológico no Brasil (1974 a 1986): do ambientalismo à ecopolítica. Revista brasileira de ciências sociais, v. 2, n. 3, 1987. p. 5-26.

ZEICHNER, Kenneth M.; PEREIRA, Júlio Emílio Diniz (Orgs.) A Pesquisa na Formação e no Trabalho Docente. Belo Horizonte: Autêntica, 2008.

Recebido em: 27 de fevereiro de 2021. Aceito em: 17 de julho de 2021. Publicado em: 05 de janeiro de 2022. 